\section{P577 ASSOCIATIONS BETWEEN PENILE-ANAL INTERCOURSE AND ORAL SEX AND VIRAL STIS IN THE UNITED STATES, 2011-2015}

${ }^{1}$ Melissa Habel, ${ }^{2}$ Jami Leichliter, ${ }^{3}$ Patricia Dittus, ${ }^{4}$ Ian Spicknall, ${ }^{1}$ Sevgi Aral. ${ }^{1}$ Centers for Disease Control and Prevention, Atlanta, USA; ${ }^{2} C D C$, Atlanta, USA; ${ }^{3} C D C$, Division of STD Prevention, Atlanta, USA; ${ }^{4}$ Centers for Disease Control and Prevention, Division of STD Prevention, Atlanta, USA

\subsection{6/sextrans-2019-sti.650}

Background Anal and oral sex are related to the acquisition and transmission of STIs, and condom use remains low for these behaviors. Thus, we examined associations between these behaviors and STIs using 2011-2015 National Survey of Family Growth data.

Methods We examined associations between male-female penile anal intercourse (PAI) and oral sex with opposite-sex partners only (lifetime) and lifetime self-report of a viral STI (herpes or genital warts) by sex and race/Hispanic origin (White, Hispanic, Black, Other). The response rate was $71.0 \%$ and sensitive survey items were asked using audio computer-assisted self-interview. Analyses were restricted to individuals reporting one lifetime sex partner. Bivariate analyses were analyzed in SUDAAN-11.0 using chi-squares.

Results Overall, more women $(12.5 \%, \mathrm{~N}=11,243)$ than men $(2.1 \%, N=9,257)$ reported ever having a viral STI. Self-report of viral STI was slightly more common among White women compared to women of other racial/ethnic groups. Among women, ever engaging in PAI was strongly associated with a viral STI diagnosis $(21.8 \%[\mathrm{SE} \quad 1.2]$ White, $20.7 \%[\mathrm{SE} 2.0]$ Black, 19.7\%[SE 3.2] Other, and 16.9\%[SE 1.7] Hispanic, $\mathrm{p}<0.0001$ ) as was giving/receiving oral sex (all 11.6\%-17.3\%). For men, the same associations differed by race/Hispanic origin. PAI was significantly associated with a viral STI in White men (5.7\%[SE 0.7], $\mathrm{p}<0.01)$, Hispanic men $(3.4 \%[\mathrm{SE} 1.0]$, $\mathrm{p}<0.05)$, and men of other racial/ethnic groups $(2.7 \%[\mathrm{SE}$ 1.2], $\mathrm{p}<0.05)$. Oral sex was associated with a viral STI in White men and men of other racial/ethnic groups; however, for Black men only giving oral sex was significantly associated with a viral STI (4.1\%[SE 1.0], p<0.05).

Conclusion For women, PAI and oral sex were related to having been diagnosed with a viral STI. Self-reported viral STIs were highest in women and Whites which may suggest disparities in health care seeking and access. Further exploration is needed to assess associations between multiple sex partners and condom use during these behaviors.

Disclosure No significant relationships.

\section{P578 DRIVERS OF SEXUAL HEALTH KNOWLEDGE FOR TWO- SPIRIT, GAY, BI AND/OR NATIVE MEN WHO HAVE SEX WITH MEN (GBMSM)}

${ }^{1}$ Harlan Pruden, ${ }^{2}$ Travis Salway, ${ }^{3}$ Jannie Leung, ${ }^{3}$ Theodora Consolacion. ${ }^{1} B C C D C$, Cps/chee Mamuk, Vancouver, Canada; ${ }^{2} B C$ Centre for Disease Control, Clinical Prevention Services, Vancouver, Canada; ${ }^{3} B C$ Centre for Disease Control, Epidemiologist, Clinical Prevention Services, Vancouver, Canada

\subsection{6/sextrans-2019-sti.651}

Background Rarely are Two-Spirit and/or Aboriginal (i.e., First Nations, Métis, and Inuit) gay, bi, or men who have sex with men (gbMSM) included in research projects that center their experiences and ways. This study examines the main drivers of sexual health knowledge (SHK) among Aboriginal $(\mathrm{N}=365)$ and Two-Spirit respondents of Sex Now 2014-15 (SN15), a national periodic survey conducted by the Community Based Research Centre for Gay Men's Health in Vancouver.

Methods Associations were examined between SHK, using a combined score of 6 survey questions, and the following explanatory variables: Two-Spirit identity, living in urban settings, income, education and gay peer networks (GPN). Correlations between explanatory variables were examined using unadjusted odds ratios, and univariate and multivariable linear regression estimated associations between each of the explanatory variables and the SHK outcome.

Results Using the Lakota expression, Mitakuye Oyasin, "all my relations," the drivers studied were interrelated: those living in urban environments had larger GPN; higher educational attainment had more income; and larger social support network had higher levels of educational attainment and larger GPN. Three main factors were positively associated as drivers of SHK: income, education, and size of GPN. Two-Spirit respondents had higher SHK than other Native men in urban settings but not in non-urban settings.

Conclusion To increase SHK with those with lower levels of education or income, or who are not connected to the "gay" community requires new ways of conducting outreach and engagement. Urban Two-Spirit folks are likely connected to one another and may get better information related to HIV prevention technologies, which may differ from those living in rural settings. Further research is needed with a larger sample and additional survey questions specific to experiences of Aboriginal gbMSM.

Disclosure No significant relationships.

\section{P579 HIGH PREVALENCE AND CORRELATES OF SYPHILIS AND HIV INFECTION AMONG ADOLESCENTS OF THE COMARCA NGÄBE-BUGLÉ, PANAMA}

${ }^{1}$ Amanda Gabster*, ${ }^{1} J u a n$ Pascale, ${ }^{2}$ Ben Cislaghi, ${ }^{1}$ Alexander Martinez, ${ }^{1}$ Alma Ortiz, ${ }^{1}$ Jorge Castillo, ${ }^{3}$ Mellissa Herrera, ${ }^{4}$ Genarino Herrera, ${ }^{5}$ César Gantes, ${ }^{5}$ Yaremis Quiel, ${ }^{1}$ Adan Ríos, ${ }^{1}$ Eliris Campbell, ${ }^{6}$ Philippe Mayaud. ${ }^{1}$ Instituto Conmemorativo Gorgas de Estudios de la Salud, Panama City, Panama; 'London School of Hygiene and Tropical Medicine, Department of Global Health and Development, London, UK; ${ }^{3}$ Caja de Seguro Social, Laboratorio de Microbiologia, Santiago, Panama; ${ }^{4}$ MINSA Capsi, La Mata, Panama; ${ }^{5}$ Ministerio de Salud, Región Comarca Ngäbe-buglé, San Felix, Panama; ${ }^{6}$ London School of Hygiene and Tropical Medicine, London, UK

10.1136/sextrans-2019-sti.652

Background The Comarca Ngäbe-Buglé (CNB), situated in western Panama, is home to over 200,000 indigenous peoples; the region has the highest levels of multidimensional poverty in the country. The prevalence and correlates of syphilis and HIV have not been previouslydescribed among adolescents of CNB.

Methods A cross sectional study, using multistage cluster sampling design with equal probability of selection and random sampling of clusters, among male and female participants aged 14-19 years, was conducted in 10 high schools in CNB from July-November 2018. A questionnaire was self-administered, participants provided blood, as well as urine and self-administered cervical/vaginal swabs for STI testing (data not shown). Serum was tested for HIV using rapid test/viral load 